\title{
Vidas: modo de usar...
}

Lives: how to use...

LORIGA, Sabina. O pequeno $x$ : da biografia à história. Belo Horizonte: Autêntica, 2011, 232 p.

\section{Mary del Priore}

marydelpriore@terra.com.br

Professora

Universidade Salgado de Oliveira

Rua Marechal Deodoro, 211 - Centro

24030-060 - Niterói - RJ

Brasil

Palavras-chave

Biografia; Escrita da História; Historiografia.

Keywords

Biography; History writing; Historiography.

\section{6}

Recebido em: 18/9/2012

Aprovado em: 23/10/2012 
A biografia, uma das primeiras formas de história - depois das dos deuses e de homens célebres - retém cada vez mais a atenção dos historiadores. Todavia, a moda da biografia histórica é recente. Com efeito, até a metade do século $X X$, sem ser de todo abandonada, ela era vista como um gênero velhusco, convencional e ultrapassado por uma geração devotada a abordagens quantitativas e economicistas. Exemplo disso é um artigo de Marc Ferro, datado de abril de 1989, em que o grande historiador francês denomina a biografia de "o aleijão" da história - "le handicapée de I'histoire". Ferro debitava esse desinteresse a duas matrizes: a da valorização do papel das massas - "sans culotte", camponeses e operários. E a diminuição do papel dos "heróis" inspirada no determinismo ou no funcionalismo, das análises marxistas e estruturalistas que marcaram a produção europeia dos anos $1960 .^{1}$

A biografia mudou ao longo dos tempos. No início era o verbo e o verbo, a narrativa. E a narrativa era história em Heródoto, mas, também, retórica, em Tucídides. Em um quanto em outro, a preocupação com o efeito literário era maior do que com a exatidão das informações. Pois o discurso, nesses casos, não tinha função de prova explicativa. Era, sim, um procedimento retórico ligado a um acontecimento histórico mais amplo. A seguir, a hagiografia encarregou-se de demonstrar a exemplaridade humana. A vida dos santos deveria incentivar modelos aos leitores. As encarnações do sagrado se tornavam modelares no percurso realizado por mártires, doutores e confessores. A partir do século XII e XIII, os santos deixaram o mundo fechado dos monastérios. A santidade passou a ser imitada no cotidiano e a narrativa sobre a vida de cavaleiros invadiu a Idade Média. Era o início de um período de heróis. Heróis, ao mesmo tempo, objetos de transferência do sagrado, atores de intrigas e portadores de valores positivos.

Com o Renascimento emergiu uma nova maneira de viver e de conceber o destino do homem no mundo. O indivíduo começou a se liberar de tutelas tradicionais que pesavam sobre o seu destino. Das leis superiores impostas por Deus, pelo Estado ou a família, tal centro voltou-se para o culto de si. O indivíduo tornou-se meta e norma de todas as coisas. ${ }^{2}$ Nos séculos seguintes, o individualismo não cessou de se afirmar. Por isso mesmo, "escrever sua vida" tornou-se moda: Marguerite de Valois, Retz, Saint-Simon entre outros memorialistas do Antigo Regime, construíam a memória do mundo e a memória de si. ${ }^{3}$ No século XVIII, o herói medieval foi substituído pelos "grands hommes" dos quais Voltaire diria: "são aqueles que se destacaram no útil ou no agradável". Contrariamente ao herói, o "grande homem" tinha que ter uma função: ser proveitoso à sociedade.

No século XIX, as biografias tiveram importante papel na construção da ideia de "nação", imortalizando heróis e monarcas, ajudando a consolidar um patrimônio de símbolos feito de ancestrais fundadores, monumentos, lugares de memória, tradições populares, etc. Esta concepção foi retomada pela corrente

\footnotetext{
${ }^{1}$ Ver FERRO (1987).

2 Vários autores trataram deste momento charneira na história ocidental. Vejam-se, por exemplo, ELIAS (1991); FOUCAULT (1987); TAYLOR (1979); TODOROV (2001); KAUFMANN (2001).

${ }^{3}$ Sobre o tema ver BRIOT (1994); FUMAROLI (1971); GUSDORF (1991a; 1991b; 1991c; 1991d).
} 
positivista. A biografia assimilou-se a exaltação das glórias nacionais, no cenário de uma história que embelezava o acontecimento, o fato. Foi a época de ouro de historiadores renomados como Taine, Fustel de Coulanges e Michelet. E também de Dilthey, Humboldt e Carlyle, autores anglo-saxônicos e menos conhecidos do público latino.

Pouco a pouco, na mesma época, história e literatura se divorciaram. A história tornou-se uma disciplina e monopólio de acadêmicos. Foi o momento do eclipse da narrativa, enterrada junto com a história factual. Nos anos 1960, a Nova História, nascida dos Annales, optou por privilegiar o "fato social total" em todas as suas dimensões: econômicas, sociais, demográficas e geográficas. E minimizar a história política, diplomática, militar ou eclesiástica que evidenciava o indivíduo e fato.

Não por acaso, na primeira metade do século, escritores como Stefan Zweig tomaram o lugar deixado vago por historiadores e investiram com entusiasmo nas biografias históricas - Maria-Antonieta, Fouché, Erasmo usando os mesmos princípios do historiador romântico Michelet, ou seja, a preocupação em recuperar "a vida total", o "drama da vida". ${ }^{4}$

Enquanto os historiadores preferiram rejeitar os ídolos individuais e os recortes cronológicos dados pelo tempo de uma existência, escritores se tornaram, então, os grandes biógrafos: Guy de Pourtalés. Gide, Michel de Leiris, André Maurois, no mundo literário francês. Lytton Strachey e Antonia Fraser, no anglo-saxão, entre outros. Convite à viagem artificial no passado, fortemente 268 ligada aos fatos, a maior parte das biografias era acrítica e lançava suas raízes no terreno das paixões coletivas. Elas correspondiam a um público ávido de fatos históricos, de acontecimentos sensacionais ou de enigmas insolúveis: na França, por exemplo, o caso do Colar da Rainha ou a desaparição do tesouro dos templários.

Foi, contudo, preciso esperar os anos 1970 e 1980 para assistir ao fim da rejeição à biografia histórica. O epistemólogo François Dosse anunciou, então, a chegada de uma "idade hermenêutica" na qual o objetivo seria capturar "a unidade pelo singular". Até que enfim, o indivíduo encontrava a história. O fenecimento das análises marxistas e deterministas que engessaram por décadas a produção historiográfica permitiu dar espaço aos atores e suas contingências novamente. Foi uma verdadeira mudança de paradigmas. A explicação histórica cessava de se interessar pelas estruturas, para centrar suas análises sobre os indivíduos, suas paixões, constrangimentos e representações que pesavam sobre suas condutas. O indivíduo e suas ações situavam-se em sua relação com o ambiente social ou psicológico, sua educação, experiência profissional, pertença étnica ou religiosa, etc.

O historiador deveria focar naquilo que os condicionava a fim de fazer reviver um mundo perdido e longínquo. Esta história, "vista de baixo", dava as costas à história dos grandes homens, motores das decisões, analisadas de

${ }^{4}$ Em entrevista à revista Nouvelles Litteraires, Zweig dizia que, para ele, a literatura "era um meio de exaltação da existência, um meio de tornar mais claro e inteligível o drama da vida". 
acordo com suas conseqüências e resultados, como a que se fazia no século XIX. ${ }^{5}$ A reabilitação da biografia histórica integrou as aquisições da história social e cultural, e com a ajuda da micro-história ofereceu aos diferentes atores históricos, uma importância diferenciada, distinta, individual. Mas não se tratava mais de fazer, simplesmente a história dos grandes nomes, em formato hagiográfico, - quase uma vida de santo, sem problemas, nem máculas. Mas de examinar os atores célebres ou não, como testemunhas, como reflexos, como reveladores de uma época. E também tensões e conflitos entre eles e seus contemporâneos.

A biografia não era mais a de um indivíduo isolado, mas é a história de uma época vista através de um indivíduo ou de um grupo de indivíduos. Ele ou eles não eram mais apresentados como heróis, na encruzilhada de fatos, mas como uma espécie de receptáculo de correntes de pensamento e de movimentos que a narrativa de suas vidas tornava mais palpáveis, deixando mais tangível a significação histórica geral de uma vida individual. ${ }^{6}$ Segundo Marc Ferro, a biografia deve muito aos estudos sobre a vida privada dos indivíduos, estudos que permitiram dessacralizar, segundo ele, os papéis estritamente públicos que esses exerceram, revelando as complexas relações entre sua vida privada e pública. Le Goff sublinha que a introdução do gênero biográfico na história atual é um instrumento útil e suplementar usado pela história cultural. É uma maneira "de continuar a fazer história por outros meios", como explicou o historiador reiteradas vezes quando interpelado sobre suas pesquisas para os estudos de São Francisco de Assis e depois, de São Luiz Rei de França. ${ }^{7}$

O estudo de muitas destas transformações da biografia, sobretudo as ocorridas no século XIX, encontramos no livro de Sabina Loriga, pesquisadora e diretora de estudos da Escola de Altos Estudos em Ciências Sociais, de Paris. A obra nasce no quadro de um seminário na mesma Escola e no caldo de inúmeros debates sobre o retorno do gênero. Sobretudo, do duelo com os pós-modernistas que insistem em dizer que a história é um gênero de ficção.

Eis porque traçar as fronteiras entre a biografia e a história, a ficção e a verdade dos fatos, por meio de obras de historiadores que buscaram a dimensão individual na história, foi o objetivo que Loriga se deu neste Pequeno $x$.... Carlyle, Wilhem Von Humboldt, Meinecke, Burckhardt, Dilthey e um escritor, Tolstói foram seus objetos de reflexão. Mas do que trata o título? A fórmula é do historiador Droysen que, em 1863, escreveu: o que denominamos de "gênio individual", ou seja, o que qualquer um é, possui e faz, deve somar-se às circunstâncias exteriores que o cercam. $O$ " $x$ " resultaria do talento individual para lidar com elas.

Daí o interesse de Loriga pelos autores oitocentistas, que se esforçaram por salvaguardar pioneiramente uma dimensão histórica para o sujeito. O período, ela explica, deu lugar a uma reflexão complexa sobre as relações emtre indivíduo e história. Muitos autores alemães não cessaram de se perguntar: o que é o

\footnotetext{
${ }^{5}$ Ver DOSSE (2005).

${ }^{6}$ Ver LE GOFF (1989).

7 Ver LE GOFF (1996).
} 
indivíduo? Como nos tornamos um? Qual a sua relação com os fatos históricos? Nada a ver com o heroísmo propalado pelo romantismo alemão, mas um estudo dos processos de individuação. Na época, no plano político, a iniciativa de tais estudos esteve associada ao sentimento de nacionalismo emergente.

Mas o que faz Tólstoi, um romancista russo, neste livro? No seu clássico Guerra e paz, tanto a estrutura quanto a abordagem narrativa refletem opiniões pessoais do autor sobre o tempo e a história. Mais, ele propõem uma infinidade de personagens "comuns", uma instabilidade interpretativa dos fatos, a análise de subjetividades e de ínfimos acontecimentos, enfim, de elementos que resultam num romance que se lê como uma narrativa historiográfica. Loriga o utiliza para refletir sobre as relações tensas entre história e literatura, sublinhando que é impossível ao historiador, renunciar à ambição de representar "a verdade histórica". O discurso histórico deve ser assertivo - ela explica. Deve funcionar como um chicote ou "uma férula", fornecendo não só informações sobre uma realidade que the é exterior, mas, ministrando, igualmente, os mecanismos para sua verificação. E discurso que valorize sempre, sempre, métodos e fontes. Confundir história e literatura pode dar errado, sobretudo, no plano estético ela cita Virginia Woolf. Porém a literatura pode nos ensinar a pluralidade que tem os significados dos fatos para os diferentes atores históricos, dependendo de sua classe social, pertença religiosa ou gênero.

Num trabalho denso que se lê como uma tese, a autora se vale de inumeráveis citações e referências às teorias em curso nas academias e escolas historiográficas. Analisa com cuidados de anatomista o que pensamos ser "literatura" para nos permitir compreendê-la diferentemente e mostrar como os historiadores trabalham com ela. A literatura é uma fonte ou um documento? Um modelo de escrita da história? Tais questões colocam a historicidade da literatura, seu valor de testemunho, seus contextos. Loriga esclarece o que fazem os historiadores quando a literatura se torna ela mesma objeto de seus estudos, demonstrando que, a cada análise, ela emerge numa relação mais densa com o social ou o político.

Apesar de cuidadosa para não tornar a linguagem hermética, Loriga não deixa de fazer um trabalho extremamente penetrante, bem demonstrativo e bem documentado sobre a literatura do século XIX, usando os estudos sociológicos de história da literatura para focar a questão da verdade do discurso histórico e suas diversas modalidades E dessa verdade nas biografias e em seus avatares.

Para concluir, vale acrescentar que tais preocupações emergem num momento em que os intelectuais franceses se perguntam se ainda sabem pensar... Depois do desaparecimento de "maîtres à penser" como Lévi-Strauss, Foucault, Barthes e Bourdieu entre outros, que impunham temas e métodos à Universidade, as ciências humanas perderam o centro. Desidrataram-se. As pesquisas de história se verticalizaram para atender às especificidades das pós-graduações. Muitas - já criticou Ronaldo Vainfas - acabam por interessar, apenas a seus próprios autores.

Na contramão desta tendência, as biografias históricas explodiram no mundo todo, mostrando que, na forma de literatura, jornalismo ou história, o assunto 
continua a interessar. Não é a toa que Sabina Loriga se sentiu interpelada por tal voga de publicações. Afinal, uma boa história, bem contada, não serve para consolar... Mas, sim, para incomodar. Longe dos efeitos inibidores de totens e tabus universitários, as histórias de vidas convidam o "maior número" a pensar sua identidade, seu passado, e a memória que se tem dele.

O pequeno $x$... é ainda mais uma publicação da editora Autêntica que vem colaborando para que cheguem ao Brasil as melhores traduções da área de ciências humanas.

\section{Referências bibliográficas}

BRIOY, Frédéric. Usage du monde, usage de soi: enquêtes sur les mémorialistes d'Ancien Regime. Paris : Seuils, 1994.

DOSSE, François. Le pari biographique: êcrire une vie. Paris : La Découverte, 2005.

ELIAS, Norbert. La société des individus. Paris: Fayard, 1991.

FERRO, Marc. La biographie, cette handicapée del ' histoire. Magazine Litteraire, n. 264, avril, 1987, p.85-86.

FOUCAULT, Michel. Le souci de soi. In: Histoire de la Sexualité. 30 volume. Paris : Gallimard, 1987.

FUMAROLI, Marc. Les Mémoires du XVIIe siècle au Carrefour des Genres en Prose. XVII Siècle, ns. 94-95, 1971.

GUSDORF, Georges Lignes de vie I. Paris: Odile Jacob, 1991a. . Les écritues du moi. Paris: Odile Jacob, $1991 \mathrm{~b}$.

- Lignes de vie II. Paris: Odile Jacob, 1991c. . Auto-biographie. Paris: Odile Jacob, 1991d.

KAUFMANN, Jean-Claude. Ego: pour une sociologie de I'individu. Paris: Nathan, 2001.

LE GOFF, Jacques. Comment écrire une biographie historique aujourd ' hui. Le Débat, 54, p. 48-53, 1989.

. Saint Louis. Paris: Gallimard, 1996.

TAYLOR, Charles. Sources du moi: la formation de I'identité moderne. Paris: Cerf, 1979.

TODOROV, Tzvetan. Éloge de I'individu: essai sur la peinture flamande de la Rennaissance. Bruxelas: Adam Biro, 2001. 